\title{
Pengetahuan Perawat Terhadap Teknik Komunikasi SBAR di Satu Rumah Sakit di Indonesia Barat
}

\author{
Meilandy Watulangkow ${ }^{1}$, Nadya Nalendra Sigar ${ }^{2}$, Rumiris Manurung ${ }^{3}$, \\ Lia Kartika ${ }^{4 *}$, Edson Kasenda ${ }^{5}$ \\ 1,2,3,4,5 Fakultas Keperawatan Universitas Pelita Harapan, Tangerang, Indonesia \\ *sarah.kartika@uph.edu
}

\begin{abstract}
Patient safety is the main thing in client's the treatment process. Nurses' knowledge or cognitive abilities are fundamental for nurses to carry out their duties and responsibilities. SBAR's effective communication technique consisting of Situation, Background, Assessment, Recommendation is known to minimize the possibility of errors in communication. This study aims to identify the description of nurses' knowledge of SBAR communication techniques. This study used a quantitative descriptive design, which was conducted from May to July 2019. The population in this study were all nurses who served in the inpatient room. The sampling technique used total sampling and involved 50 respondents. Knowledge is measured using an instrument about nurses' knowledge of effective SBAR communication techniques, valid with a Cronbach Alpha reliability of 0.851. Univariate data analysis showed that more than half of the respondents, 26 nurses (52\%), had high knowledge of SBAR communication techniques. Collaborative efforts between educational institutions and hospitals on training and simulation of SBAR communication techniques are necessary to support client safety. Further research is needed to explore the relationship between characteristics, attitudes, and motivation with SBAR implementation.
\end{abstract}

Keywords: knowledge, nurse, SBAR communication technique

\begin{abstract}
Abstrak
Keselamatan pasien merupakan hal yang utama selama klien menjalani proses perawatan. Pengetahuan atau kemampuan kognitif perawat menjadi hal yang mendasar untuk perawat mampu melaksanakan tugas dan tanggung jawabnya. Teknik komunikasi efektif SBAR yang terdiri dari Situation, Background, Assessment, Recommendation diketahui dapat meminimalkan kemungkinan kesalahan dalam berkomunikasi. Penelitian ini bertujuan untuk mengidentifikasi gambaran pengetahuan perawat terhadap teknik komunikasi SBAR. Penelitian ini menggunakan desain deskriptif kuantitatif yang dilaksanakan bulan Mei sampai dengan bulan Juli 2019. Populasi dalam penelitian ini adalah seluruh perawat yang berdinas di ruang rawat inap. Teknik sampling total sampling digunakan dan melibatkan 50 responden. Pengetahuan diukur menggunakan instrumen tentang pengetahuan perawat akan teknik komunikasi efektif SBAR yang valid dengan reliabilitas Alpha Cronbach 0,851 . Analisis data univariat menunjukkan bahwa lebih dari setengah responden yaitu sebanyak 26 perawat (52\%) memiliki pengetahuan yang tinggi mengenai teknik komunikasi SBAR. Upaya kolaboratif antara institusi pendidikan dan rumah sakit akan pelatihan dan simulasi teknik komunikasi SBAR perlu dilakukan guna mendukung keselamatan klien. Penelitian lebih lanjut diperlukan untuk menelusuri hubungan antara karakteristik, sikap, dan motivasi dengan pelaksanaan teknik komunikasi SBAR.
\end{abstract}

Kata kunci: pengetahuan, perawat, teknik komunikasi, SBAR

Jurnal Keperawatan Raflesia, Volume 2 Nomor 2, November 2020

ISSN: (p) 2656-6222, (e) 2657-1595 DOI 10.33088/jkr.v2i2.558

Available online: https://jurnal.poltekkes-kemenkes-bengkulu.ac.id/index.php/jkr 


\section{PENDAHULUAN}

Perawat merupakan petugas kesehatan yang mempunyai peran penting sebagai advokat dan pemberi asuhan keperawatan untuk setiap klien dari setiap latar belakang etnik dan agama (Smith, 2019). Peran penting lainnya yang dimiliki perawat yaitu meningkatkan dan mempertahankan kesehatan klien serta membantu mengedukasi klien mengenai pengobatan yang sedang dijalaninya serta bertanggung jawab dalam hal mengambil keputusan mengenai pelayanan yang akan diberikan bersama dengan tenaga kesehatan lain (Mulyana, 2013).

Komunikasi efektif merupakan unsur utama dalam keselamatan pasien (Achrekar et al., 2016). Kesalahan dalam berkomunikasi dapat berdampak pada keselamatan pasien selama pasien menjalani proses perawatan (Shahid \& Thomas, 2018). Unsur dari komunikasi efektif yaitu akurat, tepat waktu, jelas, lengkap, serta mudah dipahami penerima informasi sehingga dapat mengurangi kesalahan dalam komunikasi serta dapat meningkatkan keselamatan pasien (Supinganto \& Mulianingsih, 2015). Komunikasi efektif mempunyai aspek ketepatan, kejelasan bahasa maupun informasi dalam konteks yang sesuai, alurnya sistematis, serta budaya. Komunikasi tidak efektif dapat menimbulkan resiko saat memberikan asuhan keperawatan kepada pasien (Supinganto \& Mulianingsih, 2015).

Situation, Background, Assessment, and Recommendation atau dikenal dengan SBAR merupakan sebuah teknik komunikasi. SBAR terdiri dari Situation yaitu sebuah pernyataan padat terhadap permasalahan klien; Background meliputi informasi yang relevan dan singkat yang berhubungan dengan situasi; Assessment yaitu apa yang perawat temukan dan pikirkan mengenai analisis dan konsiderasi atas kondisi klien; Recommendation merujuk kepada apa yang perawat lakukan untuk dilakukan atau disarankan selanjutnya (Leonard, 2018). Teknik komunikasi Situation, Background, Assessment, Recommendation (SBAR) menjadi alat komunikasi yang handal dan valid (Shahid \& Thomas, 2018).

Implementasi SBAR meminimalisasi kejadian merugikan, meningkatkan komunikasi di antara penyedia layanan kesehatan, serta promosi keselamatan pasien di rumah sakit (Shahid \& Thomas, 2018). Teknik SBAR membantu perawat dalam memiliki komunikasi yang mudah dan terfokus selama proses serah terima pada waktu pergantian dinas. Pelaksanaan SBAR saat serah terima shift yang dilakukan di samping tempat tidur klien akan memfasilitasi komunikasi efektif antara perawat dan mendukung keselamatan klien (Achrekar et al., 2016). Studi menunjukkan bahwa implementasi teknik komunikasi SBAR di area perawatan anestesi terbukti meningkatkan komunikasi antar tenaga professional, meningkatkan iklim atau suasana kondusif akan keamanan dan keselamatan klien serta menurunkan angka kejadian yang disebabkan kesalahan dalam berkomunikasi (Randmaa et al., 2014).

Sudresti, Mustriwati, dan Kamayani (2017) menyatakan bahwa penatalaksanaan komunikasi SBAR pada tenaga kesehatan khususnya perawat berada pada kategori kurang. Dalam menyebutkan Situation hanya 39,53\%, dalam menyebutkan 
Background hanya 10,47\%, dalam menyebutkan Assessment 22,09\%, dan dalam menyebutkan Recommendation hanya $27,91 \%$. Komunikasi yang kurang dapat menimbulkan dampak negatif kepada klien. Informasi yang tidak lengkap, tidak akurat atau bermakna ambigu dapat mengarah ke kejadian salah pemberian terapi, kesalahan prosedur, penundaaan pemeriksaan diagnostik yang secara keseluruhan dapat memberi efek yang tidak diharapkan (Health Insurance Portability and Accountability Act, 2020).

Pengkajian data awal dan observasi di satu rumah sakit di Indonesia bagian Barat mendapatkan data bahwa delapan dari sepuluh staf menerapkan teknik komunikasi SBAR. Perawat mengungkapkan kenyataan di lapangan bahwa implementasi teknik komunikasi SBAR ini memakan waktu yang lama dan tidak terarah sehingga masih kerap terjadi miskonumikasi antar perawat dan dokter. Miskomunikasi yang terjadi yaitu dalam bentuk ketidakjelasan waktu pelaksanaan tindakan, waktu pelaksanaan pemeriksaan laboratorium atau pemeriksaan diagnostik. lainnya. Peneliti juga mendapatkan informasi dari pihak rumah sakit bahwa belum pernah ada studi internal terkait mutu mengenai teknik komunikasi SBAR. Berdasarkan uraian ini, peneliti tertarik untuk meneliti karakteristik dan gambaran pengetahuan perawat terhadap teknik komunikasi SBAR di satu rumah sakit di Indonesia bagian Barat.

\section{METODE}

Penelitian ini menggunakan desain deskriptif kuantitatif yang berlangsung pada bulan Mei sampai dengan Juli 2019.
Populasi dalam penelitian ini merupakan staf perawat yang bekerja di ruang rawat inap di satu rumah sakit swasta di Indonesia bagian Barat. Teknik pengambilan sampel menggunakan teknik total sampling yang melibatkan 50 perawat. Instrumen yang digunakan terdiri dari 2 bagian. Bagian pertama mencakup data demografi diantaranya: usia, jenis kelamin, tingkat pendidikan, dan pengalaman bekerja sebagai perawat. Bagian kedua terdiri dari beberapa pertanyaan untuk mengukur variabel pengetahuan tentang komunikasi SBAR. Kuesioner dikembangkan secara mandiri menggunakan teori SBAR Achrekar et al., (2016). Nilai batas kategori pengetahuan tinggi dan pengetahuan rendah menggunakan nilai rerata karena distribusi data normal. Instrumen yang dikembangkan ini telah melalui uji validitas dan reliabilitas dengan Cronbach Alpha 0.851 .

Penelitian telah mendapatkan persetujuan dari Komite Etik Fakultas Keperawatan Universitas Pelita Harapan dan disetujui dengan

No. 002/RCTC_EC/R/SHPLBANGKA/VI/201

9. Setelah persetujuan etik dan surat ijin penelitian dari rumah sakit, peneliti melakukan pengumpulan data dengan melakukan kontrak waktu dan tempat dengan perawat rawat inap. Peneliti memberikan penjelasan penelitian kepada responden terkait topik penelitian, tujuan penelitian, hak, dan petunjuk pengisian kuesioner. Responden yang sudah menyetujui akan menandatangani informed consent dan mengisi kuesioner dengan kisaran waktu tujuh sampai dengan sepuluh menit. Pengolahan data dan analisis univariat dengan teknik uji deskriptif 
dilakukan menggunakan sistem komputerisasi.

Tabel 2. Gambaran Pengetahuan Responden terhadap Teknik Komunikasi SBAR di Satu Rumah Sakit di Indonesia

HASIL

Penelitian ini melibatkan 50 responden di satu rumah sakit swasta di Indonesia bagian Barat. Tabel 1 akan memaparkan karakteristik responden berdasarkan usia, jenis kelamin, tingkat pendidikan dan pengalaman kerja.

\section{Tabel 1. Karakteristik Responden di Satu Rumah Sakit Indonesia bagian Barat} Tahun 2020 (n=50)

\begin{tabular}{lcc}
\hline Karakteristik & $\mathrm{n}$ & Persentase (\%) \\
\hline Usia (tahun) & & \\
$21-35$ & 45 & 90 \\
$36-45$ & 5 & 10 \\
$>45$ & 0 & 0 \\
Jenis Kelamin & & \\
Pria & 5 & 10 \\
Wanita & 45 & 90 \\
Tingkat Pendidikan & & \\
Diploma III & 21 & 42 \\
Sarjana & 2 & 4 \\
Ners & 27 & 54 \\
Pengalaman Kerja (tahun) & & \\
1-2 & 22 & 44 \\
3-5 & 17 & 34 \\
$>6$ & 11 & 22 \\
\hline
\end{tabular}

Tabel 1 memaparkan bahwa responden didominasi perawat yang berusia diantara 21 - 35 tahun yaitu sebanyak 45 responden (90\%) dan berjenis kelamin perempuan sebanyak 45 responden $(90 \%)$. Lebih dari setengah responden merupakan Ners yaitu sebanyak 27 responden (54\%). Data juga menunjukkan bahwa hanya sekitar 11 responden (22\%) yang memiliki pengalaman bekerja sebagai perawat diatas 6 tahun.

\section{Bagian Barat $(\mathbf{n}=\mathbf{5 0})$}

\begin{tabular}{ccc}
\hline Kategori & $\mathrm{n}$ & Persentase $(\%)$ \\
\hline Tinggi & 26 & 52 \\
Rendah & 24 & 48 \\
\hline
\end{tabular}

Tabel 2 menunjukkan bahwa lebih dari setengah responden yaitu sebanyak 26 responden (52\%) memiliki tingkat pengetahuan yang tinggi mengenai teknik komunikasi SBAR.

\section{PEMBAHASAN}

Hasil penelitian menunjukkan sebagian besar usia perawat berada di rentang usia 21-35 tahun yaitu sebanyak $90 \%$. Hal ini dapat terjadi karena rumah sakit swasta di Indonesia bagian Barat ini merupakan rumah sakit yang dalam masa berkembang, yaitu 6 tahun, sehingga sumber daya manusia masih terdiri dari perawat yang baru lulus. Pelatihan dan contoh atau role model dari perawat senior dapat membentuk perawat usia dewasa muda memiliki pemahaman yang baik tentang teknik komunikasi SBAR. Hal ini sejalan dengan Thomas dan Kunzmann (2014) yang menuliskan bahwa kebijaksanaan akan hal mendasar dalam hidup tergantung dari relevansi antara masalah normative dan usia. Sehingga setiap fase kehidupan memiliki kesempatan untuk mendapatkan kebijaksanaan selama seorang individu berkenan dan secara aktif terlibat dalam setiap tantangan hidupnya.

Responden juga didominasi oleh perawat yang berjenis kelamin perempuan yaitu sebanyak 45 responden (90\%). Seperti yang 
sudah diketahui masyarakat awam bahwa profesi perawat masih identik dengan gender perempuan. Sejalan dengan hal ini, perawat masih dikenal dengan sebuah pekerjaan yang dilakukan oleh perempuan karena perempuan memiliki sifat yang suka merawat, rendah hati, mau mengorbankan diri, pekerja keras, dan memiliki kepedulian terhadap sesama (Ozdemir, Akansel, dan Tunk 2008). Di sisi lain, pakar menuliskan bahwa keperawatan adalah tentang caring dan perasaan empati, namun sifat ini tidak mengarah secara eksklusif ke jenis kelamin perempuan (Williams, 2017).

Hasil studi lain terkait dengan tingkat pendidikan perawat di rumah sakit menunjukkan hasil bahwa lebih dari setengah responden adalah Ners Keperawatan (54\%). Peneliti berasumsi bahwa keberadaan Ners Keperawatan di sebuah rumah sakit perlu ditingkatkan.

Peneliti juga menemukan bahwa sebanyak $44 \%$ responden memiliki pengalaman kerja di rentang 1-2 tahun. Peneliti berpendapat bahwa kondisi ini menjadi tantangan untuk para perawat dapat memahami lebih lanjut tentang teknik komunikasi SBAR karena pengalaman yang cukup akan meningkatkan pengetahuan perawat tentang teknik komunikasi SBAR. Perihal ini sejalan dengan definisi pengetahuan adalah sebuah fakta atau kondisi mengetahui sesuatu melalui hubungan atau keterkaitan (Merriam Webster, 2020). Studi terkini dari Jiang et al. (2020) turut menyatakan bahwa latar belakang pendidikan memiliki hubungan yang bermakna dengan pengetahuan terkait teknik komunikasi SBAR. Hal ini didukung dengan temuan penelitian oleh Kamil (2017) yang menuliskan bahwa perawat dengan lulusan Ners Keperawatan melaksanakan teknik komunikasi SBAR di area tahapan Background dengan kategori baik yaitu sebanyak 23 responden $(95,8 \%)$.

Temuan penelitian ini menunjukkan lebih dari setengah responden yaitu sebanyak 26 responden (52\%) memiliki pengetahuan yang tinggi. Walau masih jauh dari target mutu rumah sakit yaitu sejumlah $85 \%$, peneliti berasumsi bahwa hal ini adalah hal yang baik dan berpotensi untuk mengurangi kejadian kesalahan saat serah terima dengan perawat di shift berikutnya. Hal ini sejalan dengan penelitian sebelumnya yang menunjukkan bahwa 58 orang (79\%) responden memiliki pengetahuan yang baik tentang teknik komunikasi SBAR (Irawati \& Maurissa 2015). Hasil dalam penelitian ini sejalan dengan penelitian sebelumnya yaitu lebih dari setengah responden memiliki pengetahuan tinggi tentang komunikasi SBAR yaitu sebanyak 29 perawat (51.8\%). Peneliti menyarankan untuk diadakannya penyegaran kembali yang dilakukan secara periodik kepada perawat pelaksana tentang pelaksanaan dokumentasi komunikasi SBAR untuk meningkatkan keamanan pasien (Mariani, et al., 2015). Studi dari Jiang et al. (2020) turut menuliskan bahwa perawat yang mengikuti pelatihan SBAR memiliki kenaikan nilai yang signifikan dibandingkan dengan perawat yang tidak mengikuti pelatihan teknik komunikasi SBAR. Dalam pelaksanaannya Sulistyawati dan Haryuni (2019) supervisi kepala ruangan memiliki pengaruh terhadap kualitas timbang terima informasi menggunakan teknik komunikasi SBAR. Peneliti menganjurkan agar kepala ruangan melakukan supervisi terhadap kemampuan komunikasi perawat di ruang rawat inap. 
Peneliti berpendapat bahwa responden yang memiliki pengetahuan yang tinggi yaitu responden yang mengikuti pelatihan keperawatan tentang teknik komunikasi SBAR di masa orientasi perawat baru. Lebih lanjut lagi pengetahuan akan teknik komunikasi SBAR juga dapat diterima melalui informasi dari atasan, rekan sekerja, media informasi dan pengalaman kerja perawat yang lain (Kamil, 2017). Studi terkini menunjukkan bahwa faktor yang mempengaruhi kesuksesan teknik komunikasi SBAR adalah dukungan dari pimpinan rumah sakit dan kepala ruangan, pengetahuan dan komitmen seluruh perawat juga staf lain seperti kolaborasi dengan dokter atau petugas kesehatan lainnya (Simamora \& Fathi, 2019).

Informasi tentang komunikasi SBAR ternyata tidak hanya didapatkan dari pengalaman kerja. Institusi pendidikan yang memberikan simulasi tentang teknik komunikasi SBAR kepada mahasiswa sarjana ternyata memberikan pengaruh yang baik. Sun dan Goo (2019) menyatakan bahwa program edukasi melalui skenario dan bermain peran efektif untuk meningkatkan pengetahuan dan efikasi diri mahasiswa keperawatan tentang teknik komunikasi SBAR. Lebih lanjut lagi, studi terkini menunjukkan bahwa teknik komunikasi SBAR sebagai perangkat komunikasi turut meningkatkan kepercayaaan diri mahasiswa keperawatan selama berkomunikasi dengan perawat senior, dan petugas kesehatan lainnya (Stevens et al., 2020). Penelitian oleh Achrekar et al. (2016) menuliskan bahwa sebagian besar perawat (79\%) perawat di ruang rawat inap mengungkapkan bahwa teknik komunikasi SBAR sangat bermanfaat dalam pelaksanaan serah terima informasi dengan perawat berikutnya.

Perawat perlu memperhatikan beberapa hal dalam mengimplementasikan teknik komunikasi SBAR. Kusumaningsih dan Monica (2019) dalam studinya menganjurkan agar perawat tidak menjelaskan informasi di dekat pasien dengan suara yang lantang. Perawat juga diharapkan menggunakan bahasa yang dipahami oleh klien atau tidak menggunakan bahasa yang baku serta tidak lupa untuk memperkenalkan diri kepada klien saat melakukan teknik komunikasi SBAR. Hidajah dan Harnida (2017) turut juga menuliskan bahwa rumah sakit dapat melakukan beberapa upaya untuk meningkatkan komunikasi efektif antara lain dengan cara pemberian modul tentang komunikasi efektif dan pelatihan komunikasi kepada perawat di ruangan. Hal ini bertujuan untuk dapat meningkatkan mutu pelayanan keperawatan di ruang rawat inap.

Selain kebermanfaatan dari teknik komunikasi SBAR, penelitian menunjukkan bahwa terdapat keterbatasan penggunaan teknik komunikasi SBAR untuk klien dengan riwayat perjalanan medis dan perencanaan keperawatan yang kompleks khususnya dalam tatanan keperawatan kritis (Shahid \& Thomas, 2018). Implementasi perangkat SBAR ini membutuhkan pelatihan yang khusus untuk semua staf pelaksana agar teknik komunikasi ini benar-benar dapat dipahami dengan baik. Struktur dari bentuk komunikasi membutuhkan penyesuaian dengan perubahan kultur dari semua penyedia layanan kesehatan (Shahid \& Thomas, 2018). 


\section{KESIMPULAN}

Hasil penelitian menunjukkan bahwa lebih dari setengah responden memiliki pengetahuan yang tinggi terhadap teknik komunikasi SBAR. Peneliti berharap agar institusi pendidikan dapat memperdalam konsep tentang teknik komunikasi SBAR ini dan memfasilitasi mahasiswa keperawatan bersimulasi menggunakan teknik komunikasi ini sehingga dapat mendukung kesiapan mahasiswa menjadi perawat professional di masa yang akan datang. Perawat di tatanan klinik diharapkan tetap konsisten menerapkan teknik komunikasi SBAR ini selama proses serah terima pasien untuk mendukung keselamatan pasien. Kolaborasi dengan pihak rumah sakit juga diperlukan untuk dapat memberikan pelatihan kepada perawat novice dan penyegaran kepada perawat ruangan tentang simulasi teknik komunikasi SBAR agar dapat mencapai standar mutu rumah sakit yaitu sekitar $85 \%$. Rekomendasi untuk peneliti selanjutnya adalah meneliti hubungan karakteristik, sikap dan motivasi perawat dengan pelaksanaan teknik komunikasi SBAR agar komunikasi tetap efektif dan keselamatan klien terjamin.

\section{DAFTAR PUSTAKA}

Achrekar, M., Murthy, V., Kanan, S., Shetty, R., Nair, M., \& Khattry, N. (2016). Introduction of Situation, Background, Assessment, Recommendation into Nursing Practice: A Prospective Study. Asia-Pacific Journal of Oncology Nursing, 3(1), 45. https://doi.org/10.4103/23475625.178171

Hidajah, U., \& Harnida, H. (2017). Peran Komunikasi SBAR dalam Pelaksanaan
Handover di ruang rawat inap RSPS. NersMid, 72-81.

Health Insurance Portability and Accountability Act. (2020). Effects of Poor Communication in Healthcare. Health Insurance Portability and Accountability Act. https://www.hipaajournal.com/effects-ofpoor-communication-in-healthcare/

Irawati, \& Maurissa, A. (2015). Pengetahuan perawat terhadap teknik komunikasi SBAR di rsud dr. Zainoel Abidin Banda Aceh. 1-5.

Jiang, N., Luo, X., Zhou, Y., Huang, J., Zhao, W., Liu, Q., Yang, Y., Zhang, S., \& Deng, X. (2020b). A Study on the Knowledge of SBAR of Clinical Nurses in Hospital Blood Glucose Management. American Journal of Nursing Science, 9(4), 225. https://doi.org/10.11648/j.ajns.20200904. 19

Kamil, H. (2017). Pelaksanaan komunikasi SBAR di rumah sakit umum daerah Banda Aceh. Jurnal Ilmiah Mahasiswa Fakultas Keperawatan, 2(3).

Kusumaningsih, D., \& Monica, R. (2019). Hubungan komunikasi SBAR dengan pelaksanaan timbang terima perawat di ruang rawat inap rsud dr. A. Dadi Tjokrodipo bandar Lampung tahun 2019. Indonesian Journal of Health Development, 1(2), 25-35.

Leonard, M. (2018). SBAR Tool: SituationBackground-Assessment-

Recommendation. IHI - Institute for Healthcare Improvement. http://www.ihi.org/resources/Pages/Tools /sbartoolkit.aspx

Mariani, P. D., S, I. W., \& L, E. (2015). Analisis Faktor yang Mempengaruhi Pelaksanaan Komunikasi SBAR dalam Rekam Medis Terintegrasi Ruang Rawat inap III Rumah Sakit Panti Rapih Yogyakarta Februarimaret 2014. Jurnal Kesehatan, 2(2), 6672.

Merriam Webster. (2020). Knowledge | 
Definition of Knowledge. MerriamWebster Dictionary. https://www.merriam-

webster.com/dictionary/knowledge

Mulyana, D. S. (2013). Analisis Penyebab Insiden Keselamatan Pasien oleh Perawat di Unit Rawat Inap Rumah Sakit X Jakarta. Universitas Indonesia, 3.

Ozdemir, A., Akansel, N., \& Tunk, G. (2008). Gender and career: Female and Male Nursing Students. Perceptions of Male Nursing Role in Turkey. Health Science Journal, 2(3), 133-161.

Randmaa, M., Mårtensson, G., Swenne, C. L., \& Engström, M. (2014). SBAR Improves Communication and Safety Climate and Decreases Incident Reports Due to Communication Errors in an Anaesthetic Clinic: A Prospective Intervention Study. BMJ Open, 4(1), 1-8. https://doi.org/10.1136/bmjopen-2013004268

Shahid, S., \& Thomas, S. (2018). Situation, Background, Assessment, Recommendation (SBAR) Communication Tool for Handoff in Health Care - A Narrative Review. Safety in Health, 4(1), 1-9. https://doi.org/10.1186/s40886-0180073-1

Simamora, R. H., \& Fathi, A. (2019). The Influence of Training Handover Based SBAR Communication for Improving Patients Safety. Indian Journal of Public Health Research and Development, 10(9), 1280-1285. https://doi.org/10.5958/09765506.2019.02755.4

Smith, Y. (2019). Roles of a Nurse. News Medical Life Sciences. https://www.newsmedical.net/health/Roles-of-a-Nurse.aspx

Stevens, N., McNiesh, S., \& Goyal, D. (2020). Utilizing an SBAR Workshop With Baccalaureate Nursing Students to Improve Communication Skills. Nursing Education Perspectives, 41(2), 117-118.

Sudresti, N., Mustriwati, K. A., \& Kamayani, M. O. (2017). Hubungan Penggunaan Komunikasi SBAR dengan Kualitas Pelaksanaan Bedside Handover. Community of Publishing in Nursing
(COPING), 5, 73-80.

Sulistyawati, W., \& Haryuni, S. (2019). Supervisi tentang Komunikasi SBAR (Situation, Background, Assesmen and Recommendation) Berpengaruh terhadap Kualitas Handover Pasien di Ruang Rawat Inap Rumah Sakit. Care : Jurnal Ilmiah Ilmu Kesehatan, 7(1), 19. https://doi.org/10.33366/jc.v7i1.1111

Sun, L. O., \& Goo, N. Y. (2019). The Relationship among Knowledge of SBAR, Attitudes towards SBAR, and Critical thinking Disposition for Nursing Students. Journal of Digital Convergence, 17(9), 213-220. https://doi.org/10.14400/JDC.2019.17.9. 213

Supinganto, A., \& Mulianingsih, M. (2015). Identifikasi Komunikasi Efektif SBAR (Situation, Background, Assessment, Recommendation) Di RSUD Kota Mataram. Jurnal Keperawatan (Publikasi).

Thomas, S., \& Kunzmann, U. (2014). Age Differences in wisdom-related knowledge: Does the age relevance of the task matter? Journals of Gerontology Series B Psychological Sciences and Social Sciences, 69(6), 897-905. https://doi.org/10.1093/geronb/gbt076

Williams, R. (2017). Why are there so few male nurses? The Guardian. https://www.theguardian.com/healthcarenetwork/2017/mar/01/why-so-few-malenurses 